Article

\title{
Assessing the Effectiveness of Building Information Modeling in Developing Green Buildings from a Lifecycle Perspective
}

\author{
Quan Wen ${ }^{1,2}$, Zhongfu Li ${ }^{1, *}$, Yifeng Peng ${ }^{3}$ and Baorong Guo ${ }^{4}$ \\ 1 Department of Construction Management, Dalian University of Technology, Dalian 116000, China; \\ wenquan@mail.dlut.edu.cn \\ 2 School of Management, Shenyang Jianzhu University, Shenyang 110000, China \\ 3 School of Construction Management and Real Estate, Chongqing University, Chongqing 400045, China; \\ 20200301015@cqu.edu.cn \\ 4 School of Business Administration, Northeastern University, Shenyang 110000, China; \\ 1910439@stu.neu.edu.cn \\ * Correspondence: lizhongfu@dlut.edu.cn
}

Received: 9 October 2020; Accepted: 27 November 2020; Published: 29 November 2020

\begin{abstract}
Building information modeling (BIM) is an emerging technique in the construction industry. It is regarded as an effective approach for green building development; however, its effectiveness has not been sufficiently investigated from a lifecycle perspective. To bridge this research gap, this study investigates BIM application value in different phases of a green building through a convolutional neural network (CNN) method. To begin with, an assessment framework was developed with the consideration of balancing the estimation accuracy and the data size. Then, the validity of the developed model was verified from both theoretical and practical perspectives. Finally, the effectiveness of BIM was tested using the proposed framework. Results showed that the overall score of the tested project was four in the five-point Likert scale, with an average relative error less than $1 \%$. From a value-based perspective, it is revealed that the application value of BIM represented a descending order throughout the lifecycle of the tested project. In addition, it is found that the functional value obtained the highest score, whereas social value was at the bottom. The findings of this study can help decision makers to detect the weaknesses of BIM implementation during green building development.
\end{abstract}

Keywords: green buildings; building information modeling; application value; CNN model

\section{Introduction}

Building-related primary energy consumption is the major driver responsible for global climate change. Globally, it accounts for nearly half of aluminum consumption, more than $40 \%$ of steel consumption, and $20 \%$ of commodity energy consumption [1,2]. As a consequence, mitigating adverse environmental impact from the building sector is challenging. In China, buildings consumed nearly $28 \%$ of the country's total energy from a life cycle perspective, with the operational stage alone accounting for approximately one-fifth [3,4]. In this circumstance, green building (GB), which refers to places that invest great efforts in less resource-intensive materials, techniques, devices, and services in comparison with traditional buildings, has received growing attention from industry practitioners and academic researchers [5-7]. To date, relevant research on GB mainly includes four aspects, namely, (1) GB definition, which entailed great efforts in conceptualizing the function, organization, and structure of GB from construction and environmental perspectives [8,9]; (2) GB evaluation, which focused on developing life cycle evaluation tools for obtaining GB rating and certification [10,11]; 
(3) GB optimization, which aimed to improve the schedule, cost, and productivity performance and minimizes the potential risk of GB projects [12-14]; and (4) green technology implementation, which proposed to detect the synergy, feasibility, and effectiveness of advanced technology in promoting GB performance [15]. Current studies feature an in-depth discussion of the notation, development, certification, and management of green buildings with a wide range of practical demonstrations.

However, with the rapid development of information, integrating information technology with green buildings is important. Building information modeling (BIM), which is characterized by data-intensive and intelligent features, is a computer-based process for visualizing and simulating a facility, with advantages in information extraction and analysis $[16,17]$. BIM allows the integration and sharing of multidisciplinary knowledge that covers architecture and engineering, thus benefiting life cycle building optimization [18]. Consequently, integrating BIM with green buildings alleviates information isolation in the design, construction, and operation stages, which can help achieve a balance between green technology and green management [19].

A vast body of work has focused on the challenges and opportunities toward future scenarios brought by BIM implementation in buildings [20,21]. BIM technology takes advantages in providing real-time and visual-aid simulation data and intuitive visualization information, so as to facilitate knowledge exchange and sharing between departments, and to reduce the design alteration and construction rework of a project [22]. Previous research has made intensive investigations of life cycle benefits induced by implementing BIM [23], including planning optimization and site selection [24,25], collaborative design efficiency improvement [26,27], dynamic onsite construction management [28], and innovative property management [29].

Furthermore, integrating information technologies into the GB domain has raised concern worldwide [30]. From a demand perspective, green buildings require integrated simulations with due consideration of energy use, daylighting, and ventilation, which place the compatibility, particularly that related to the incorporation of relevant software and data for visualization, under great pressure. Thus, BIM implementation enables the coordination of technologies from multiple sources and improves collaboration accuracy and efficiency among stakeholders. From a life cycle perspective, BIM achieves integrated management among different life cycle stages, which is conceptually consistent with the GB that is committed to achieve life cycle green management [29]. Specifically, achieving sustainable objectives of green buildings needs a comprehensive and systematic understanding of information for materials and devices [31]. BIM technology provides integrated solutions for coordinating and optimizing such information to achieve energy conservation and emission reduction of buildings. Given the similarity and feasibility of BIM in energy and environmental performance analysis, studies attempted to apply BIM in green buildings.

Regarding research objects, Ansah, et al. [32] indicated that BIM applications in green buildings concentrated on energy simulation, carbon emission assessment, indoor and outdoor environmental quality analysis, light pollution assessment, and renewable materials quantification. Gao, et al. [33] developed a BIM-based building energy modeling (BEM) method by investigating data transmission between BIM and BEM. On this basis, Pezeshki, et al. [34] extended MEM by arguing that lacking interoperability between BIM and BEM would impede the development and delivery of energy projects. Jalaei and Jrade [35] developed an automatic model to investigate environmental impacts and embodied energy use of building components by combining BIM, life cycle assessment, energy simulation tool, and GB rating system. From a life cycle perspective, BIM applications may involve the exchange and sharing of information in the design, production, construction, and operation stages of green buildings. For instance, El-Diraby, et al. [36] made use of BIM-enabled GB design method and GB analytical tools to optimize the design by simulating solar radiation, daylighting, natural ventilation, and acoustics. Wong and Zhou [29] built a BIM-assisted supervision system for green construction by collecting onsite management data with GIS positioning, LIDAR, and point-cloud techniques. Chen, et al. [37] created a 3D modeling method to achieve visualized supervision and multilayer warning during the operation of green buildings. 
However, previous research has focused on the practical and empirical application of BIM in green buildings, and there is a lack of an in-depth understanding of the effectiveness of BIM implementation from a lifecycle perspective. An accurate and time-efficient assessment of the application value of BIM is beneficial for identifying practical effectiveness and realistic problems in the decision-making process involved in projects. Thus, this study aims to evaluate the application value of BIM in different stages of a green building.

To detect the effectiveness of technology application, traditional estimation methods such as analytic hierarchy process (AHP), neural network method, data envelopment analysis (DEA), and support vector machine (SVM) are normally used. Table 1 shows the basic principle and features of each method. In fact, AHP has been widely used in effectiveness evaluation that help the researcher facing a complex problem with multiple conflictions and subjective criteria. However, this method relies on subjective judgment, thus suffering from biases from experts [38,39]. DEA utilizes a linear programming method to address the joint effects of multiple input and output variables on efficiency estimation [40]. However, this method has weaknesses in non-linear fitting. In addition, the estimation derived from SVM is determined by the number of support vectors instead of the dimension of data, thus being limited by convergence rate and resource availability [41]. Compared with other counterparts, the neural network analytical method is effective in resolving non-normal non-linear assessment issues without the restriction of rational assumptions [42]. This method has advantages in non-linear mapping, self-learning, and generalization when encountering machine-learning-related problems [43]. Against this backdrop, neural networks are widely adopted in estimating and predicting the effectiveness of technology implementation [44,45].

Table 1. Comparative analysis of different assessment methods.

\begin{tabular}{cll}
\hline Method & \multicolumn{1}{c}{ Principle } & \multicolumn{1}{c}{ Feature } \\
\hline AHP & $\begin{array}{l}\text { A model for providing comprehensive } \\
\text { results by adopting paired comparisons } \\
\text { between items and criteria }\end{array}$ & $\begin{array}{l}\text { Capable of accommodating multiobjective, } \\
\text { multistandard, multifactor, and multilevel } \\
\text { complex issues in qualitative and } \\
\text { quantitative systems }\end{array}$ \\
\hline DEA & $\begin{array}{l}\text { A linear programming method to assess } \\
\text { the efficiency by measuring the distance } \\
\text { relative to a non-parametric frontier }\end{array}$ & $\begin{array}{l}\text { Capable of transferring multiple variables } \\
\text { into one efficiency score index without } \\
\text { knowing the information on } \\
\text { variable weights }\end{array}$ \\
\hline SVM & $\begin{array}{l}\text { A dualistic classification-based } \\
\text { generalized linear classifier by processing } \\
\text { data with supervised learning }\end{array}$ & $\begin{array}{l}\text { Feasible for scenarios with appropriate and } \\
\text { representative real data without } \\
\text { pre-assumption of independence between } \\
\text { the input features }\end{array}$ \\
\hline BP neural network & $\begin{array}{l}\text { A multilayer dynamic feed-forward } \\
\text { network to predict the results by } \\
\text { minimizing the disparities between } \\
\text { estimations and the actual data }\end{array}$ & $\begin{array}{l}\text { Embedded with strong learning ability and } \\
\text { data storage ability with the input layer, } \\
\text { hidden layer, and output layer }\end{array}$ \\
\hline
\end{tabular}

Despite the superiority of neural network in estimations, further improvements can be made from a theoretical perspective [46]. Therefore, convolutional neural network (CNN) has been developed by combining the advantages of deep learning, which enables to mitigate the reliance on subjective judgment by expertise. This method is a feed-forward neural network armed with convolutional computation allowing for shift-invariant classification [47]. To date, $\mathrm{CNN}$ is widely applied in image identification, defect recognition, and object detection [48,49]. However, this method may suffer from poor consistency between actual and predicted estimations when the training set is insufficient. In this study, CNN is employed to automatically identify the life cycle features of BIM implementation with a comparatively large scale of the training set.

In summary, to address the misinterpretation of real application value of BIM in green buildings, this study employed CNN to detect life cycle performance of BIM by establishing an integrated 
assessment framework that covers the design, construction, and operation stages. The findings of this study can provide solid foundations for value-oriented improvement strategies and deepen the integration of BIM with green buildings, which is beneficial for achieving green and information-led industrial transitions in the construction industry.

\section{Methods and Data Collection}

\subsection{Framework Development}

This study develops a CNN-based assessment framework for evaluating the effectiveness of BIM application in green buildings. The whole framework can be divided into three subsystems from a life cycle perspective, namely, design, construction, and operation subsystems (See Figure 1). In the framework, the core values needed to be maximized, and the stakeholders involved for value improvement vary as the stages change, which is result of the evolutionary dynamics of green buildings [50]. Based on previous research, we have preliminarily summarized the possible actors influencing the BIM application in green buildings. Subsequently, we took a further step to identify the most influential actors for the BIM application by interviewing professionals and experts from academia and industry. In this survey, 200 questionnaires were distributed and 182 of them were collected with the response rate at $81.5 \%$. The interviewees were firstly required to select the most influential actors for BIM application in green buildings. Then they were required to allocate all core actors into different lifecycle stages. As a result, the core actors influencing the application value of BIM in the design stage of green buildings are investors, the public, and end-users. In the construction stage, the core actors include clients, designers, contactors, and surrounding communities that are possibly influenced by the target project. In the operation stage, the core actors consist of end-users, investors, property companies, and the public. In general, the purpose of BIM application in green buildings is to achieve the sustainability in building's whole lifecycle. As a result, the values we aimed to achieve by BIM implementation, undoubtedly, are highly related to the triple-bottom-line sustainability, namely the intrinsically interacted economic, environmental, and social aspects of buildings [51]. Apart from this, additional types of values should be further identified by taking into consideration the distinct features of BIM and green buildings. To achieve this, a comprehensive literature review is taken to identify key value factors during a building's whole life cycle. Iacovidou et al. [52] indicated that BIM is capable of digitalizing functional information and can enhance the safety management performance of a building project. Barni, et al. [53] demonstrated the importance of multientity (e.g., physical) value network in the whole value chains during digitalization process. Marefat et al. [54] demonstrated the positive effect of BIM in managing safety in construction projects. Bosch et al. [55] emphasized the importance of BIM for maintaining and managing the operation stage of buildings. Therefore, in addition to the economic (EV), environmental (EnV), and social values (SV), this study also examines the functional (FV), physical (PV), safety (SaV), and management values (MV) of BIM application in green buildings.

On the basic principles of value breakdown system, this study summarized factors that may influence the value performance of green buildings at different stages (See Table 2). The draft factor index was developed by reviewing previous research relevant to the effectiveness assessment of BIM application. Then the factor index was further refined and improved by inviting professionals and experts from industry and academia. 


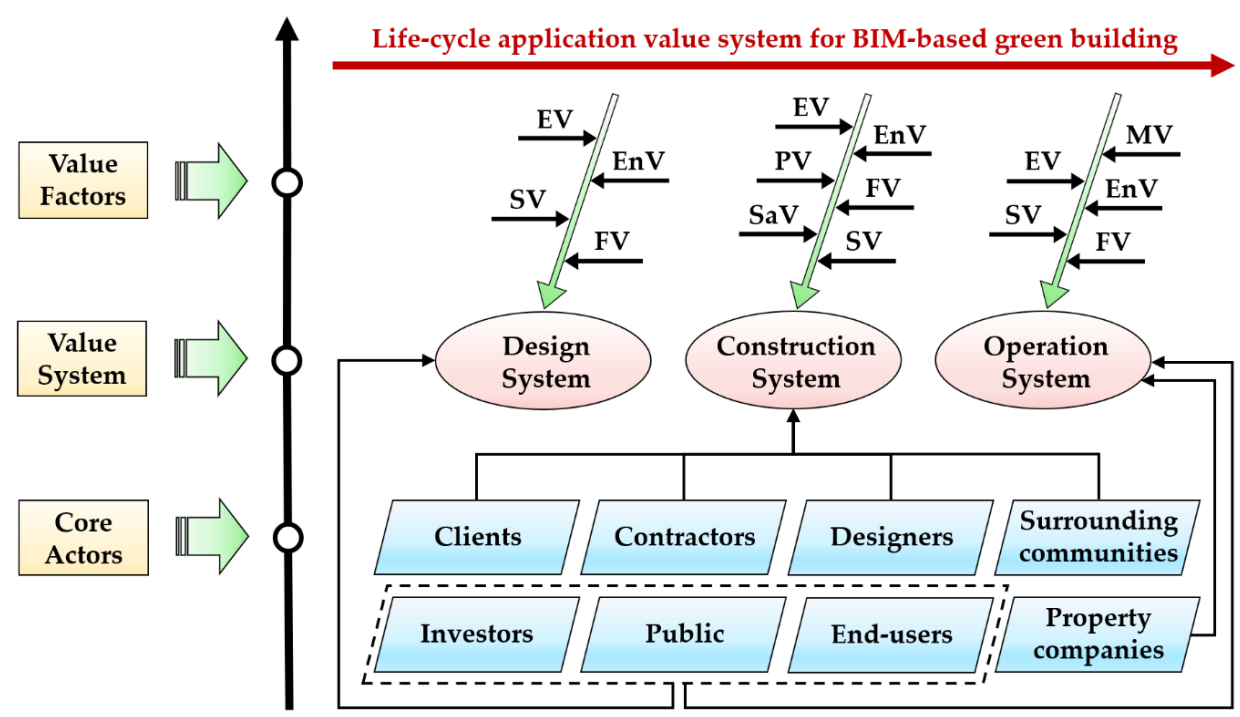

Figure 1. Integrated framework for life cycle value assessment of building information modeling (BIM) implementation in green buildings.

Table 2. Factors influencing value performance and their related actors.

\begin{tabular}{|c|c|c|c|c|}
\hline Stages & Factors & Codes & Description & Actors \\
\hline \multirow{13}{*}{ Design } & \multirow{4}{*}{ EV } & EV1 & Investment return and interest payable & $\operatorname{In}^{1}$ \\
\hline & & EV2 & Improve capital and resource efficiency & In; $\mathrm{P}^{2}$ \\
\hline & & EV3 & Save design cost and reduce design errors & In; $E^{3}$ \\
\hline & & EV4 & $\begin{array}{l}\text { Achieve long-term development with } \\
\text { low-investment risk }\end{array}$ & In \\
\hline & \multirow{3}{*}{ FV } & FV1 & $\begin{array}{l}\text { Improve stability, durability, and feasibility } \\
\text { of buildings }\end{array}$ & E \\
\hline & & FV2 & $\begin{array}{l}\text { Technical convenience and service quality by } \\
\text { using BIM }\end{array}$ & $\mathrm{E} ; \mathrm{PC}^{4}$ \\
\hline & & FV3 & Technical coordination by using BIM & $\mathrm{E} ; \operatorname{Con}^{5}$ \\
\hline & \multirow{3}{*}{ SV } & SV1 & Save public expenditure & $\mathrm{P}$ \\
\hline & & SV2 & Improve public cognition of BIM & $\mathrm{P}$ \\
\hline & & SV3 & Accelerate green building evaluation process & $\mathrm{P}$ \\
\hline & \multirow{3}{*}{ EnV } & EnV1 & $\begin{array}{l}\text { Minimize negative impacts on atmosphere, } \\
\text { waterbody, acoustic, and bio-ecology through } \\
\text { elaborated design }\end{array}$ & In; $P$ \\
\hline & & EnV2 & Improve the surrounding natural environment & In; $P$ \\
\hline & & EnV3 & Improve the efficiency of natural resource utilization & In; P \\
\hline \multirow{9}{*}{ Construction } & \multirow{3}{*}{ EV } & EV1 & Minimize construction cost & $C^{6}$ \\
\hline & & EV2 & $\begin{array}{l}\text { Achieve profit balance between different } \\
\text { stakeholders }\end{array}$ & $\mathrm{D}^{7} ; \mathrm{Con}$ \\
\hline & & EV3 & Improve financial performance & $\mathrm{C}$ \\
\hline & \multirow{3}{*}{ PV } & PV1 & Optimize construction quality & $\mathrm{C}$ \\
\hline & & PV2 & Meet the schedule of target objectives & $\mathrm{C}$ \\
\hline & & PV3 & Achieve target design functions & Con \\
\hline & \multirow{3}{*}{$\mathrm{SaV}$} & SaV1 & Ensure onsite construction safety & $\mathrm{C}$ \\
\hline & & SaV2 & Prevent serious safety accidents & C; Con \\
\hline & & SaV3 & Ensure the safety of surrounding communities & $\mathrm{SC}^{8}$ \\
\hline
\end{tabular}


Table 2. Cont.

\begin{tabular}{|c|c|c|c|c|}
\hline Stages & Factors & Codes & Description & Actors \\
\hline & \multirow{5}{*}{ FV } & FV1 & Apply clean and new energy technology & C; Con \\
\hline & & FV2 & $\begin{array}{l}\text { Optimized design with room for further } \\
\text { development }\end{array}$ & $\mathrm{D}$ \\
\hline & & FV3 & Drawings have good workability & $\mathrm{D}$ \\
\hline & & FV4 & Technical innovation in construction management & Con \\
\hline & & FV5 & $\begin{array}{l}\text { Feasibility and maturity of new construction } \\
\text { technologies }\end{array}$ & Con \\
\hline & \multirow{3}{*}{ SV } & SV1 & $\begin{array}{l}\text { Minimize negative influence on surrounding } \\
\text { communities }\end{array}$ & SC \\
\hline & & SV2 & $\begin{array}{l}\text { Achieve coordination, cognition, and approval from } \\
\text { surrounding communities }\end{array}$ & SC \\
\hline & & SV3 & Compensation for people harmed by the project & SC \\
\hline & \multirow{4}{*}{$\mathrm{EnV}$} & EnV1 & Use of green materials & Con \\
\hline & & EnV2 & $\begin{array}{l}\text { No serious pollution caused in surrounding sites } \\
\text { during construction }\end{array}$ & $\mathrm{C}$ \\
\hline & & EnV3 & Reduce unnecessary use of natural resources & Con \\
\hline & & EnV4 & Protect local ecological and natural environment & SC \\
\hline \multirow{19}{*}{ Operation } & \multirow{5}{*}{ EV } & EV1 & Desirable operational profit & PC \\
\hline & & EV2 & Reduce operational cost & PC \\
\hline & & EV3 & Stable operational financial support & In \\
\hline & & EV4 & High investment return rate & In \\
\hline & & EV5 & Price of products and services & PC; E \\
\hline & \multirow{3}{*}{ SV } & SV1 & Improve technical standard and specification of BIM & PC; In \\
\hline & & SV2 & $\begin{array}{l}\text { Advance green building evaluation for } \\
\text { operational stage }\end{array}$ & $\mathrm{P} ; \mathrm{PC}$ \\
\hline & & SV3 & Enhance certification of end-users & $\mathrm{E} ; \mathrm{P}$ \\
\hline & \multirow{4}{*}{$\mathrm{EnV}$} & EnV1 & $\begin{array}{l}\text { Improve surrounding ecological and natural } \\
\text { environment }\end{array}$ & $\mathrm{P}$ \\
\hline & & EnV2 & $\begin{array}{l}\text { Minimize impacts on atmosphere, waterbody, } \\
\text { acoustic, and bio-ecology with elaborated operation }\end{array}$ & $\mathrm{E} ; \mathrm{P}$ \\
\hline & & EnV3 & Use of green facilities and devices & PC; E \\
\hline & & EnV4 & Improve natural resource utilization efficiency & PC; E; P \\
\hline & \multirow{3}{*}{ FV } & FV1 & Achieve green performance of buildings & $\mathrm{E} ; \mathrm{P}$ \\
\hline & & FV2 & Improve renewal ability of projects & PC; E \\
\hline & & FV3 & $\begin{array}{l}\text { Improve operational and technical capability } \\
\text { of projects }\end{array}$ & PC; P \\
\hline & \multirow{4}{*}{ MV } & MV1 & Building information management & PC; E \\
\hline & & MV2 & Improve equipment management & PC \\
\hline & & MV3 & Enhance public safety management & $\mathrm{PC}^{4} ; \mathrm{E}^{3}$ \\
\hline & & MV4 & Improve smart management & $\mathrm{PC}^{4} ; \mathrm{E}^{3}$ \\
\hline
\end{tabular}

\footnotetext{
${ }^{1}$ In: investors, ${ }^{2} \mathrm{P}$ : the public, ${ }^{3} \mathrm{E}$ : end-users, ${ }^{4} \mathrm{PC}$ : property companies, ${ }^{5}$ Con: contractors, ${ }^{6} \mathrm{C}:$ clients, ${ }^{7} \mathrm{D}$ : designers,

8 SC: surrounding communities.
}

\subsection{Development of CNN-Based Assessment Model}

The whole computational model consists of three parts. The first part involves data collection and consolidation, which aims to obtain input data from questionnaire surveys. The survey is based on a five-point Likert scale, in which experts are instructed to give intuitive points on all indicators. 
The second part proposes to develop a CNN-based computational model, which will be detailed in the next section. The third part validates the feasibility of the developed model in a real case.

The traditional computational process of neural network is developed by the multiply operation of matrix with weights automatically allocating to input, intermediate, and output variables individually. This manipulation has undoubtedly increased the number of parameters. In contrast, CNN can minimize the number of parameters and thus alleviate workload by integrating the convolutional layer and pooling layer, thereby improving calculation efficiency. Applying CNN for assessment has several advantages. First, $\mathrm{CNN}$ has outperformed in model robustness and fault tolerance in the translation, rotation, and scaling of eigenvectors. Second, BIM provides a huge amount of real-time and visual-aid simulation data and intuitive visualization information. $\mathrm{CNN}$ can directly consolidate the multidimensional raw data for characteristic extraction without the data preprocessing in the traditional neural network analysis. Third, conventional methods are restricted by the limited accessibility for characteristic information, whereas the input variables selected in this study have a large number of implicit features portraying application value of life cycle BIM implementation, which are inappropriate in traditional analysis. Consequently, developing a structured and self-adaption CNN model is crucial to achieve accurate estimations.

CNN's advantage is in self-learning, which is beneficial for moderating the dependence of subjective extraction of data characteristics. Consequently, this network model enables an in-depth analysis of the mapping relationship between original input data and final assessment results via extracting the hidden features embedded in the input information. Figure 2 shows the logic procedures for adopting CNN in life cycle assessment of BIM implementation in green buildings, which includes three components and 10 layers.

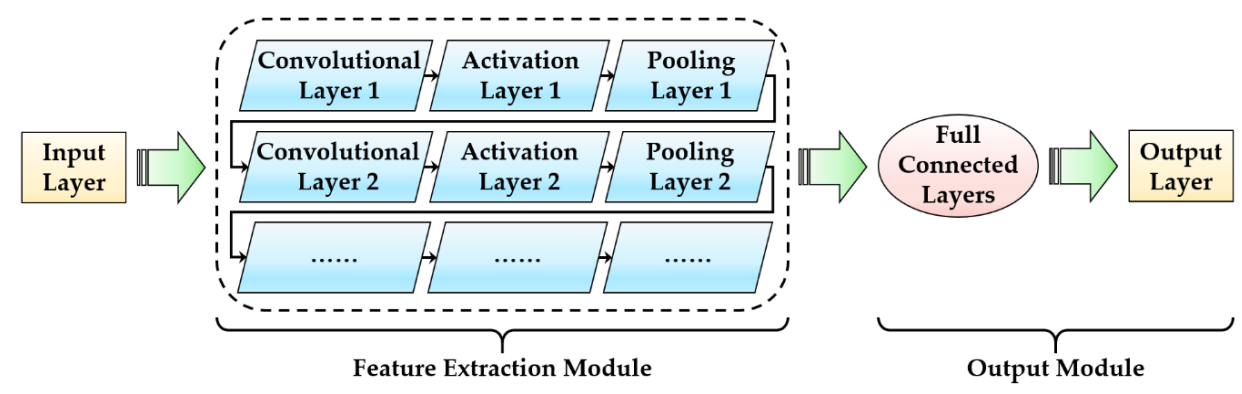

Figure 2. Basic procedures of convolutional neural network (CNN) model [56].

The most important component of $\mathrm{CNN}$ is the feature extraction modular, which is composed of three parts, namely, the convolutional layer, activating layer, and pooling layer. The convolutional layer is the core of the extraction modular, which is designed for the convolutional operation of input data, aiming to enhance data effectiveness and minimize the negative effect from data noise. Unlike the traditional neural network analysis that requires mutual interactions between each input neuron and output neuron, each convolutional kernel only needs partial connections, which is beneficial for improving computational speed and prediction accuracy.

The convolutional equation can be expressed as:

$$
M_{j}=\sum_{i=1}^{n} H_{i} \times W_{i j}+b_{j}
$$

where $j$ is the number of output feature map, $n$ is the number of the convolutional kernel, $M_{j}$ is the $j$ th output feature map after the convolutional operation, $H_{i}$ represents the $i$ th feature map of the input unit connected to the convolutional kernel, $W_{i j}$ is the weight matrix of the $i$ th unit in all input units connected to the $j$ th feature map of the convolutional kernel, the symbol $\times$ represents the convolutional operation, $b_{j}$ represents the $j$ th bias term of the feature map. 
However, the aforementioned convolutional operation is normally used to describe linear changes, which is weak to understand non-linear issues. To address this problem, CNN integrates activating layer by introducing non-linear activating functions, such as Sin function, Gaussian function, and Relu function. Compared with other functions, Relu function performed better in taking rapid derivative of target variables, reducing the interdependence of parameters, and alleviating the overfitting phenomenon [57-60]. Therefore, this study employed Relu function for further analysis.

The pooling layer functions to compress the data by minimizing the data dimension. This manipulation can reduce calculation workload, accelerate data training speed, and avoid overfitting in the training set. This study follows the criterion developed by Hyvarinen and Koster [61], who successfully reduced data dimension by adopting a high-value selection system, where the entire data pooling was divided into a set of parts in which the highest value in each pooling receptive field was selected as the representative value to minimize data dimension.

The output layer includes five nodes in accordance with the five-point Likert scale adopted in this study. The Softmax activating function is adopted to obtain outcomes, which can be expressed as:

$$
S_{i}=\frac{e^{Y_{i}}}{\sum_{j} e^{Y_{j}}}
$$

where $Y$ is a binary variable with values at zero or one. Similarly, to detect the difference between the probability distribution of estimations obtained from training process and real cases, this study employed a log-likelihood function, where a lower value of the function indicates smaller disparities between them. The equation can be formed as:

$$
H=-\frac{1}{n} \sum_{k=1}^{m} y_{i, k} \log \left(p_{i, k}\right)
$$

where $n$ is the number of samples, and $m$ denotes the total assessment types, which is equal to five in this study. $y_{i, k}$ is a binary variable with values equal to one or zero, which reflects whether the actual grade evaluated by experts to a specific sample is in line with the $k$ th assessment type. $p_{i, k}$ is the probability of predicted sample $i$ belonging to the $k$ th assessment types.

Based on aforementioned layers, CNN can be used to assess the effectiveness of life cycle BIM implementation in green buildings. On the one hand, the assessment of BIM application in green buildings involves indicators from multiple dimensions and different lifecycle stages, which are labeled with non-normal and non-linear features. On the other hand, $\mathrm{CNN}$ is feasible to address machine learning-related quantitative assessment. This method allows better performance on non-linear mapping, self-learning, and generalization compared with other machine learning algorithms. As a consequence, it is efficient in processing non-normal and non-linear, and multidimensional data obtained for assessing BIM application in green buildings [62]. CNN includes two steps, namely, offline training and online prediction. Figure 3 shows the detailed procedures. The purpose of offline training is to obtain parameters and form the mature model for the next-step analysis. To achieve this goal, a large number of data are collected from field surveys among clients, investors, contractors, designers, end-users, general public, property companies, supervisors, and people from surrounding communities. These data are used as the input data set. Subsequently, the collected data are divided into the training set and testing set, which are regarded as the input data for the convolution layer, activation layer, pool layer, and full connection layer to determine the most appropriate model for assessment. Specifically, the testing set is used to examine the difference between the estimated and actual distributions, which aims to update model parameters. After completing the training process, the online prediction can be achieved by importing the real data from realities. 


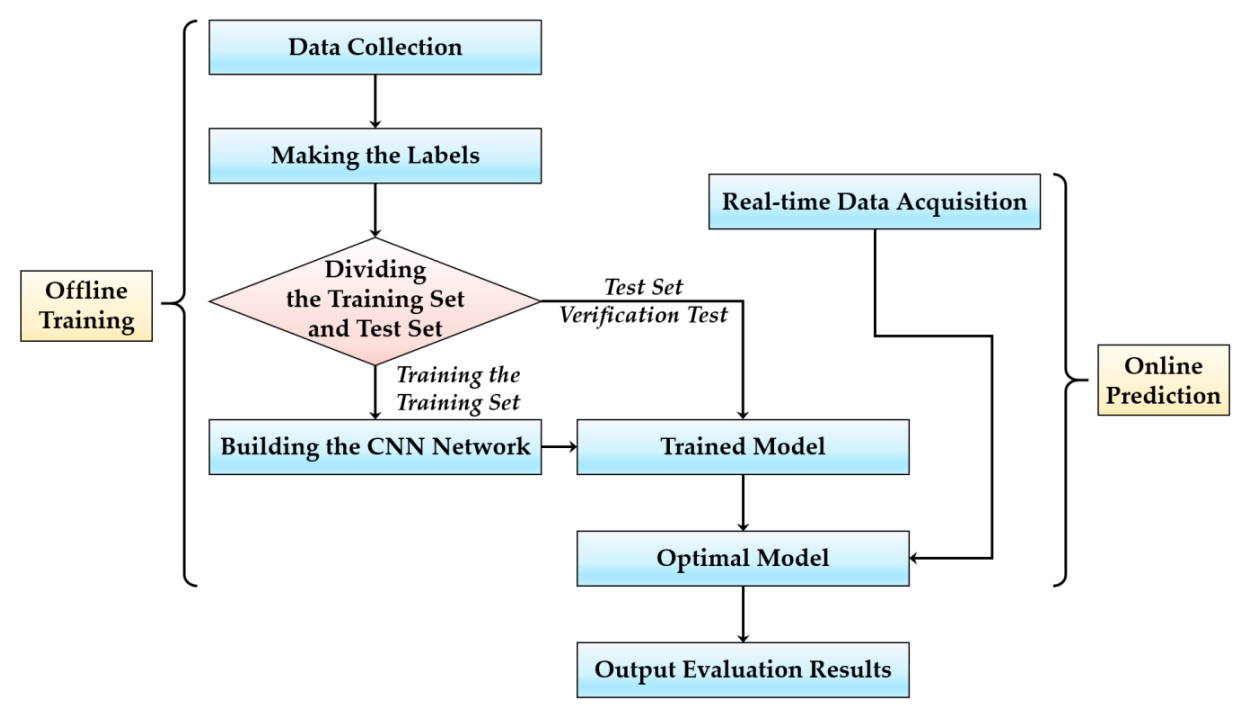

Figure 3. Basic procedures of offline training and online prediction.

\subsection{Model Validation}

To examine the validity of the developed CNN-based assessment model for evaluating effectiveness of life cycle BIM implementation in green buildings, this study tests the accuracy, consistency, and reliability by adopting the comparative analysis, Kappa coefficient, and F1-Score. Specifically, this study aims to compare estimation results derived from this study with those obtained from BP neural network, SVM method, and an AHP-based evaluation to illustrate the accuracy of the developed model. For the detailed computational process of the above three methods, please refer to supplementary file Section S1.

To test the consistency between actual divisions and predicted estimations, the Kappa coefficient is adopted on the basis of a confusion matrix with the value ranging from -1 and 1 [63], which can be calculated as:

$$
K=\frac{N \sum_{i=1}^{R} x_{i i}-\sum_{i=1}^{R}\left(x_{i+}, x_{+i}\right)}{N^{2}-\sum_{i=1}^{R}\left(x_{i+}, x_{+i}\right)}
$$

where $R$ is the assessment category, $x_{i i}$ is an element located at the diagonal, $x_{i+}$ denotes the sum of the $i$ th row, $x_{+i}$ represents the sum of the $i$ th column, and $N$ is the sum of all elements. Finally, the coefficient $K \leq 0$ means poor consistency of estimations, $0<K \leq 0.4$ means slight, $0.4<K \leq 0.55$ indicates fair, $0.55<K \leq 0.7$ means good, $0.7<K \leq 0.85$ means very good, and $0.85<K$ means excellent.

In general, the reliability of the developed CNN model is determined by precision, recall rates, and F1 score [64,65]. Precision presents the probability of actual positive samples in the estimations that are predicted to be positive. Similarly, recall indicates the probability of estimations that are predicted to be positive in all the actual positive samples. However, the value of precision rate and recall rate cannot be maximized simultaneously given their theoretical contradictions. As a consequence, F1-score is designed to indicate the reliability of estimations by obtaining a balance between the precision rate and recall rate.

\subsection{Data Collection and Consolidation}

To obtain reliable survey data, this study combines five-point Likert scale with PLanguage method. Here 1 point means poor effectiveness of BIM application in green buildings, 2 points means slight, 3 points means fair, 4 points means good, and 5 points means excellent. Specifically, the PLanguage method instructs the perception of assessment boundary for interviewees by providing a four-level description with keywords including MUST, PLAN, WISH, and MAX (See Table 3). Subsequently, the Likert scale has been assigned in the corresponding assessment intervals distinguished by the PLanguage method (See Figure 4). According to the influencing factors listed in Section 2.1, 
a questionnaire has been designed. The corresponding strategies to avoid misunderstanding of interviewees are adopted to enhance the validity and reliability of the questionnaire. The original questionnaire was modified and improved by conducting a pilot survey with experts and professionals from the industry and academia. A total of 2115 questionnaires were distributed to the targeted interviewees, and 2000 of them were collected with a $94.6 \%$ response rate. Before the data analysis, we need to preprocess the data to check whether there are invalid samples and outliers. If there is a large amount of missing data or too many similar answers in the same sample, such samples should be treated as invalid samples. After a subjective screening, 1682 questionnaires were determined valid with a validity rate of $84.1 \%$.

Table 3. Keywords in PLanguage method.

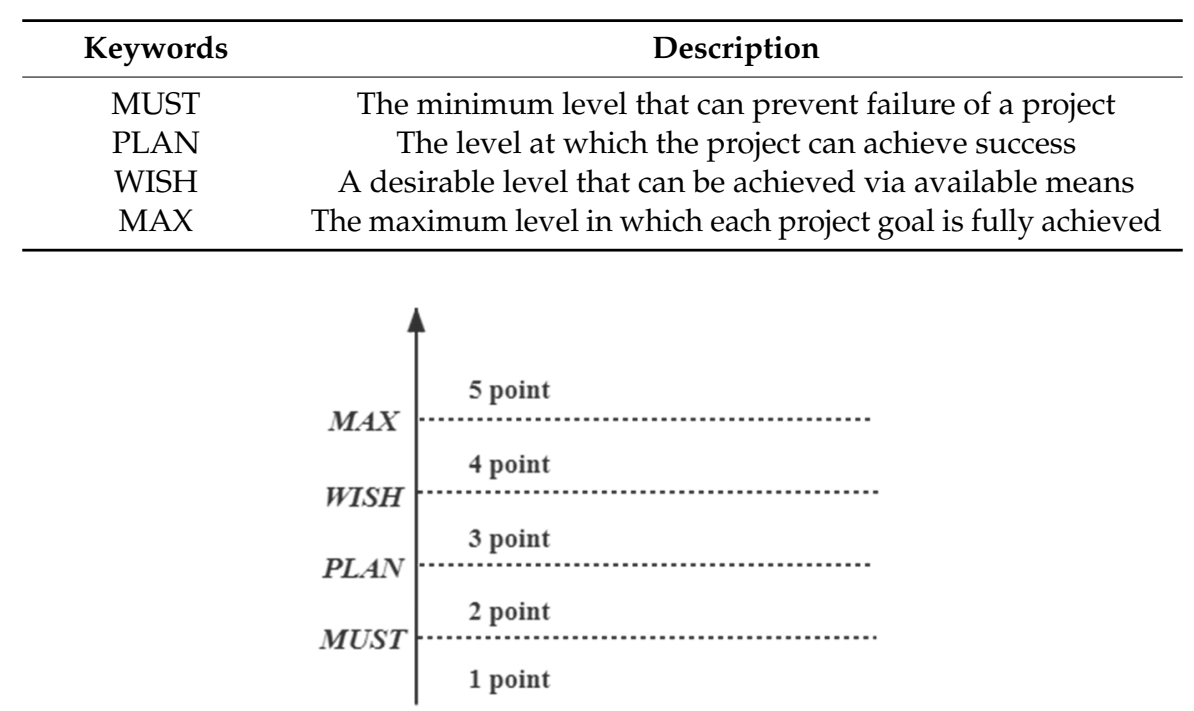

Figure 4. Assessment intervals of the Likert scale.

The sample set was randomly divided into the training set with 1300 questionnaires and the testing set with the remaining 382 questionnaires. Figure S1 in the supplementary file shows the empirical value distribution of the total questionnaire, training set, and testing set.

\section{Model Training and Improving}

Figure 5 represents the model fitting process with the training and testing data. Figure 5 a shows that the information losses declined sharply after 10 rounds of iterations and converged toward zero after 20 rounds of iterations. Similarly, according to Figure $5 b$, the estimation accuracy rapidly improved with the increasing of iterations, and gradually stabilized at $99.4 \%$ after 15 iterations. In summary, the parameters of $\mathrm{CNN}$ achieved an equilibrium state after approximately 20 rounds of iterations, indicating that the current $\mathrm{CNN}$ has labeled with the requisite features of life cycle BIM implementation in green buildings.

The detailed results for validation process are shown in the supplementary file Section S3. In terms of model accuracy, the CNN model outperforms in value prediction with an accuracy rate of $99.4 \%$, followed by BP neural network (96.4\%), SVM model (95.2\%), and AHP-based assessment (91.2\%). The results of consistency analysis indicate a relatively high consistency among different assessment results with the Kappa coefficient at 72.6\%. Moreover, according to Figure S3, the results of reliability analysis reveal that the developed CNN model obtains high precision, recall, and F1 score for each predicted score point, indicating that the developed $\mathrm{CNN}$ model performs with more confidence and higher accuracy when the target project is featured with high effectiveness of BIM application. 


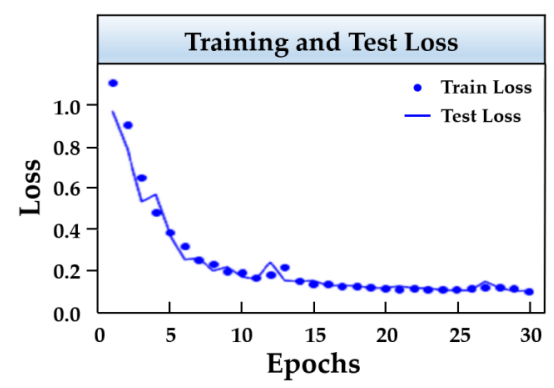

(a)

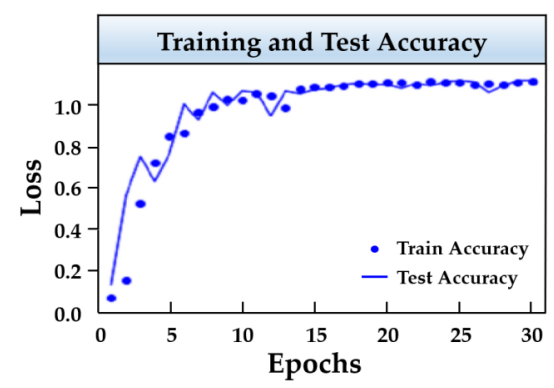

(b)

Figure 5. Model fitting process. (a) describes the changes of information losses; (b) describes the changes of estimation accuracy.

\section{Empirical Analysis}

\subsection{Case Study}

To verify the feasibility of the developed assessment model, this study uses an affordable housing project located in Shenzhen as a case study. The target construction project has $64,627.52 \mathrm{~m}^{2}$ in total gross floor area and $11,162.98 \mathrm{~m}^{2}$ in total land area. The total investment is 313.6 million RMB, and includes 945 units of apartments. Table 4 shows the basic profile of the target project.

Table 4. Basic profile of the target project.

\begin{tabular}{ccc}
\hline Category & Indicator & Case Project \\
\hline \multirow{3}{*}{ Geographic information } & Location & Shenzhen \\
& Temperature & $2{ }^{\circ} \mathrm{C}$ \\
& Climate & Subtropical \\
\hline & Build type & Residential \\
& Construction period & May 2015-December 2016 \\
Building information & Structure & Frame shear structure \\
& Gross floor area $\left(\mathrm{m}^{2}\right)$ & $64,627.52$ \\
& Basement & 1 floor \\
& Height & $31-33$ floors \\
\hline Green Building & Rainwater collecting & $\sqrt{ }$ \\
& Greening rate & $30 \%$ \\
& Green Building Evaluation Label & Two stars \\
& Pollutant concentration & Class I (GB 50235-2010) \\
\hline & Main tools & Revit, Allplan \\
& Architectural Model & $\sqrt{ }$ \\
& Structure Model & $\sqrt{ }$ \\
\hline
\end{tabular}

The reasons for selecting this construction project are listed as follows. First, this project adopted BIM as a technical assistance during the entire life cycle of buildings, covering the design, construction, and operation stages. Each stage has achieved the standard, modular, and systematic management by using BIM technology. Second, this project has earned a two-star GB label for design, which provides solid foundations for evaluating the effectiveness of life cycle BIM implementation in green buildings. Specifically, this project adopted BIM technology to achieve an integration design by coordinating electromechanical, decoration, architecture, and structure design, which improved collision-detecting effectiveness. In the production stage, a BIM-assisted mold design system was developed to facilitate the production layout in the offsite factory, which was capable of automatically offering mapping, computation, processing, and production service. In the construction stage, BIM was implemented to systematically simulate onsite construction process with the purpose of improving assembly effectiveness and quality by resolving construction-related problems in advance. In the operational stage, a BIM-integrated operational platform is adopted to sustain the basic functions and performance of buildings, and to ensure the daily operation, maintenance, assets, and property management of buildings. Figure 6 shows the detailed life cycle BIM implementation in the target project. 


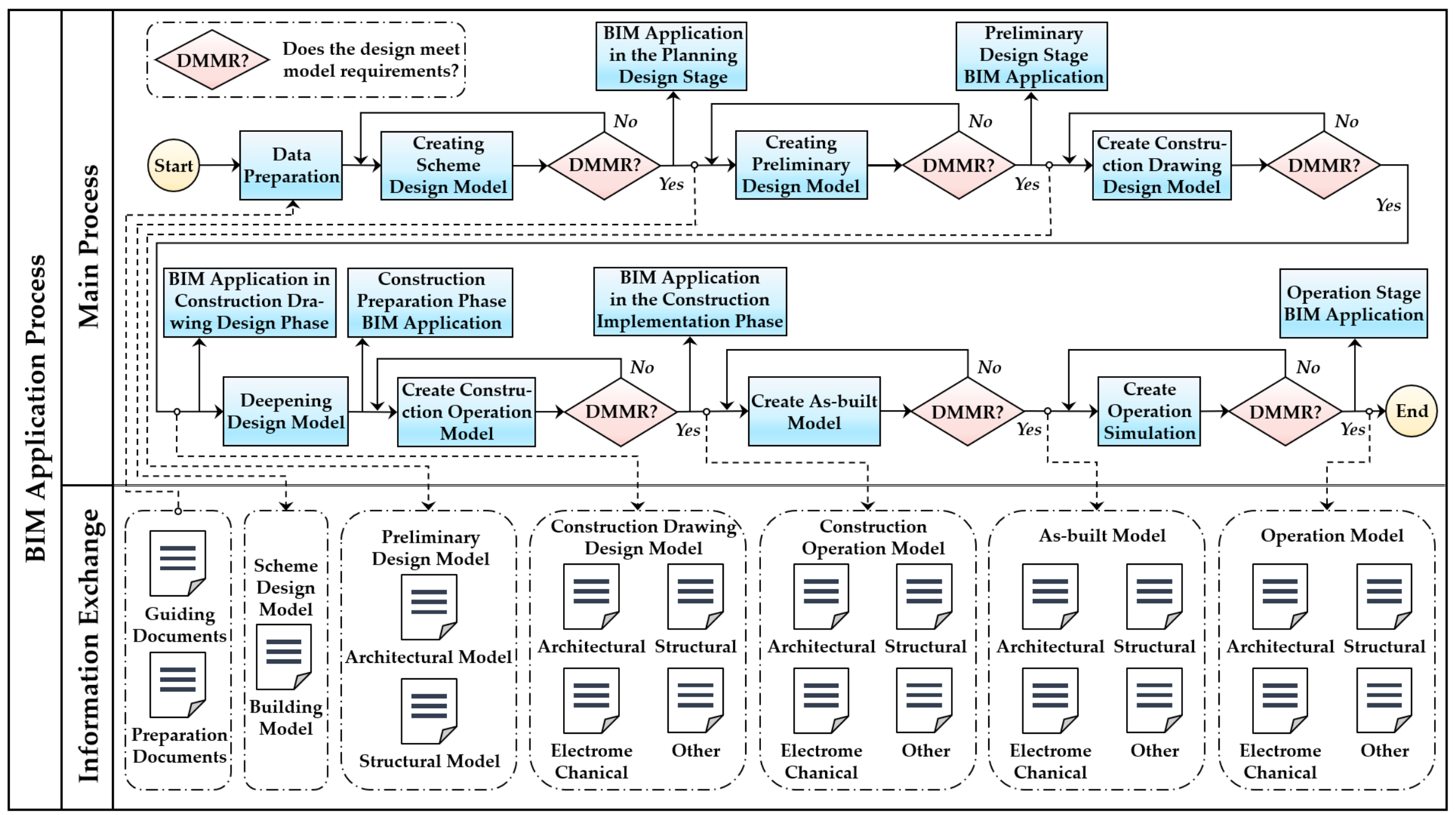

Figure 6. Life cycle BIM implementation in the target construction project. 


\subsection{Results and Discussions}

This study collected 300 questionnaires as testing set for the target case study by conducting another round of field survey. The involved respondents included the investors, the public, end-users, property companies, contractors, clients, designers, and surrounding communities. For the interviewees involved in construction practice, the respondents should meet at least one of the following criteria: (1) More than three years of working experience; (2) Obtain relevant qualifications in the construction field; (3) Qualified as junior manger or above. For the interviewees from the public, end-users or surrounding communities: (1) Have basic knowledge on building construction; (2) Understand information technology in construction practice; (3) Be affected by the target project implementation. Then, the previously trained CNN network is used to evaluate the value of BIM technology applications in case projects. According to Table 3, the model results show that the overall score for the tested project was four, with an average relative error of less than $1 \%$. More than half of assessments were predicted as four (58.3\%), followed by two (33.0\%) and five (11.0\%).

From a life cycle perspective, Figure 7 summarizes the effectiveness of BIM implementation according to different life cycle stages. The estimated application values for design stage, construction stage, and operation stage are at five, four, and three, respectively. Such a descending order of values indicates that BIM application value is fully achieved in the design stage but has declined in the construction and operation stages. This fact is highly related to the dilemma of GB rating in China, where most of certificated green buildings are efficient only in the design stage and perform unreliably in the operational stage. Thus, the design stage receives more concerns than other life cycle stages, because most GB projects in China are sold-led buildings, where the assurance of operational performance is beyond the responsibility of developers. As a result, clients lack motivation to conduct operational environmental improvements after the delivery. Moreover, BIM technology can maximize its value by visualizing and simplifying the complexity of buildings at the design stage. Likewise, the construction process can benefit from the parameter optimization with the assistance of $3 \mathrm{D}$ visualization derived from BIM. In contrast, the operation and maintenance of buildings with BIM are supported by reconfiguring data and information from the design and construction stages. Such maintenance faces major challenges in multisource data integration, model simplification, and function development, leading to a lower application effectiveness of BIM. Furthermore, to take a close examination of score distribution with due consideration of value characteristics, this study simulates the value distribution by reducing data dimensions using t-distributed stochastic neighbor embedding (t-SNE) as an underlying method. The color of the dots represents the values of assessment, which is a 2D reflection of high-dimensional assessment values. According to Figure $7 \mathrm{~b}$, in the construction stage, the size of bottom-score (e.g., one point) clustering and top-score (e.g., five point) clustering are negligible. On the one hand, this phenomenon indicates that the BIM implementation is far from ineffective, where the embedded functions, such as conflict detection, construction simulation, and quantity survey, are relatively mature. On the other hand, further improvements on BIM application can be made in the construction stage. In the operation stage, the dots valued at five represent a more discrete distribution, which indicates that multiple improvement paths exist for achieving a higher application effectiveness of BIM.

Similarly, from a value-based perspective, functional value obtains the highest score, whereas the social value is at the bottom with the output score at two (See Figure 8). Given the technical advantages of BIM in realizing virtual reality and digital simulation, its big contributions to functional improvement of green buildings are easy to understand. The lower score of social value reveals that new technologies always face social challenges before their diffusion and popularization among the public.

The 2D score distribution of values explores similar trends (See Figure 9), where the score distribution of functional value (FV) is inclined to cluster and it occupied the largest area, indicating a higher application value of BIM for function improvement. In contrast, other value categories, 
including physical value (PV), safety value (SaV), and management value (MV), represent a discrete distribution and small concentration of low scores, indicating poorer performance than counterparts.

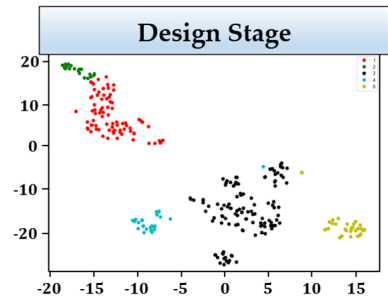

(a)

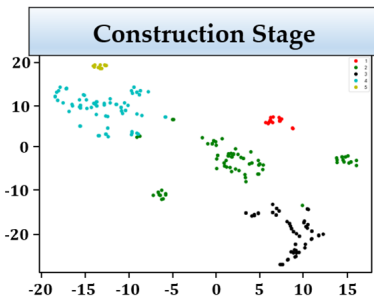

(b)

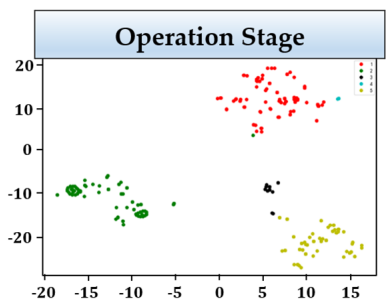

(c)

Figure 7. Effectiveness of BIM implementation in different life cycle stages. (a) Design stage; (b) Construction stage; (c) Operation stage.

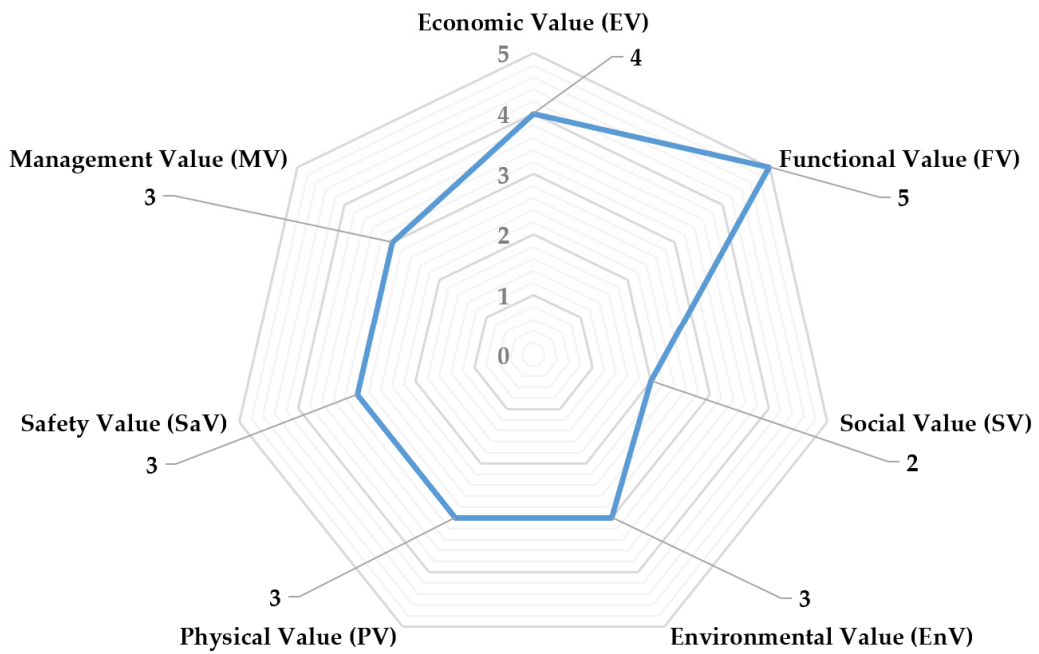

Figure 8. Scores for different values.

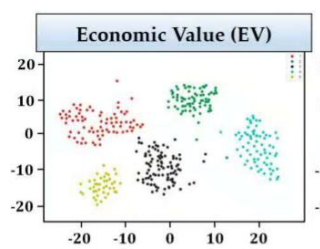

(a)

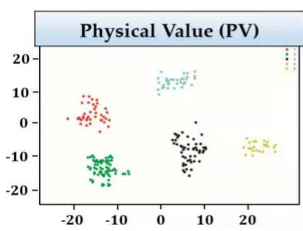

(e)

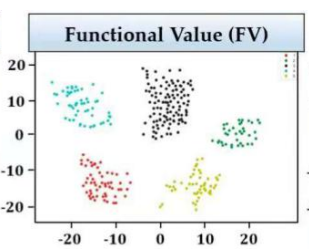

(b)

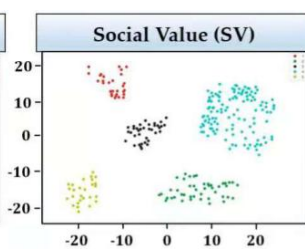

(c)

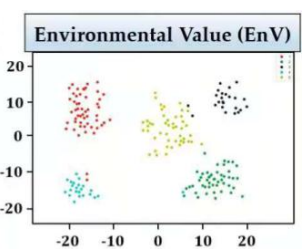

(d)

Figure 9. Effectiveness of BIM implementation for different values. (a) 2D score distribution of economic value (EV); (b) 2D score distribution of functional value (FV); (c) 2D score distribution of social value (SV); (d) 2D score distribution of environmental value (EnV); (e) 2D score distribution of physical value (PV); (f) 2D score distribution of safety value (SaV); (g) 2D score distribution of management value (MV). 
Figure 10 shows a more detailed decomposition of score for each application value in each stage. Functional value has occupied the top position in all stages and achieved the maximum value at the design and construction stages. This result indicates that integrating BIM with green buildings is beneficial for achieving the green performance of energy, material, water, and land use in the whole life cycle. Social values perform the worst in GB life cycle stages. Thus, how to improve public awareness of the active role of BIM in GB design, how to reduce negative impact on the surrounding environment, and how to advance green performance during building operational stage are challenges that need to be tackled in the near future. Furthermore, the environmental function is lowest in the operation stage, which reemphasizes the weakness of GB rating in the operation stage.

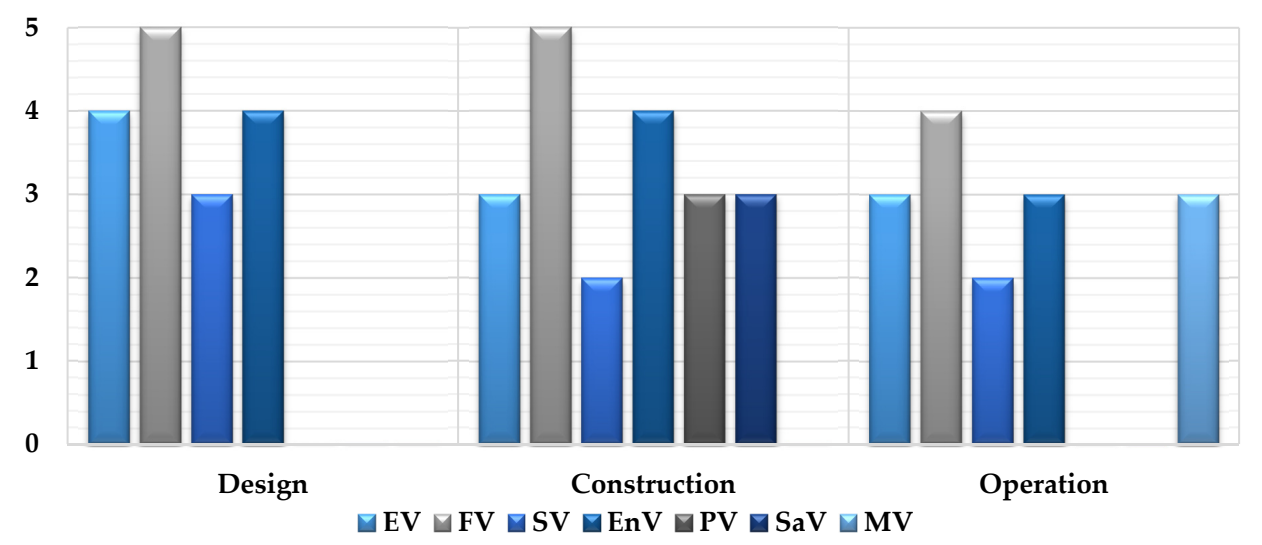

Figure 10. Scores of different values in different life cycle stages.

Figure 11 shows the 2D distribution of scores. Two obvious trends can be observed. First, although functional value obtains a high score in all stages, a clustering trend can be found between the five-point dots and one-point dots. That is, functional value can possibly transfer its score from high to low. This possibility is mainly because, despite advanced technical support offered by the BIM, the relevant working experience on BIM implementation in green buildings is also crucial for determining the performance of functions, which is currently rare in construction practice. Second, the high-score distribution of functional value and social value is more discrete than the other values, indicating large disparities between eigenvectors representing excellent performance (e.g., five point). Such a variation reveals multiple paths capable of achieving the excellence of functions. Moreover, the weakness of social function is demonstrated by the dominant distribution of dots with low values. Therefore, improving social function is a critical path for promoting the effectiveness of life cycle BIM implementation in green buildings.

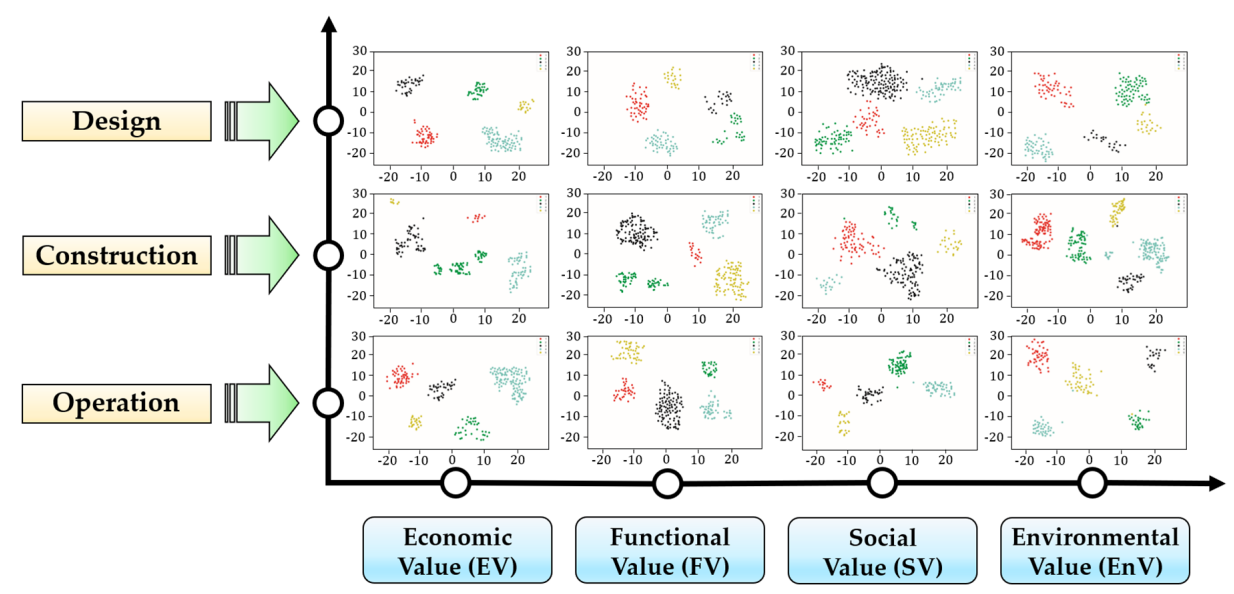

Figure 11. 2D score distribution of values in different life cycle stages. 


\section{Conclusions}

This study develops a CNN-based method for assessing the application value of BIM in green buildings. An efficient framework is developed for balancing the estimation accuracy and size of input data, thus minimizing the time and cost for the data collection process. The validity of the developed model has been verified from theoretical and practical perspectives. An elaborate design of the computational framework and the field survey reveal that integrating the PLanguage method with a five-point Likert scale can provide a clear conceptual boundary for subjective assessment, which improves the quality of input data to a large extent. By using different assessment methods, this study proves that the CNN model predicts higher estimation accuracy than the BP neural network, SVM method, and AHP-based assessment. The verification of the developed model in a real case demonstrates that this model could perform robust and reliable results even with time and sample size constraints. The key findings of this study include the following aspects:

(1) From a life cycle perspective, the effectiveness of BIM implementation in green buildings represents a descending order, indicating that application value of BIM is fully achieved in the design stage but has declined in the construction and operation stages.

(2) From a value-based perspective, functional value obtains the highest score, whereas the social value is at the bottom, indicating that BIM takes advantages in functional realization while suffering from challenges from its diffusion and popularization among the public.

(3) A detailed examination reveals that functional value has occupied the top position in all stages and achieved the maximum value at the design and construction stages, indicating that integrating BIM with GBs is beneficial for achieving the green performance of energy, material, water, and land use in the whole life cycle.

(4) Both social and environmental values perform relatively low in GB life cycle stages, which put emphases on enhancing the public awareness of the active role of BIM in GB and promoting the BIM application for environmental improvements.

The findings of this study can facilitate decision makers to detect weaknesses of BIM implementation in green buildings. Specifically, the superiority of CNN method allows better performance on non-linear mapping, self-learning, and generalization compared with other machine learning algorithms, which is efficient in processing the multidimensional raw data obtained for assessing BIM application in green buildings. Consequently, practitioners can obtain an in-depth understanding of benefits and weaknesses of BIM application in green buildings even with time and sample size constraints. The rapid development of information technology and the continued emphasis on sustainability in China allow a deeper integration of BIM in lifecycle management of green buildings, especially considering the accelerated development of green building certification in China. Therefore, identifying an evolutionary path for reinforcing the effectiveness of lifecycle BIM implementation in green buildings is crucial. Future research directions should focus more efforts on adopting system dynamic techniques to simulate the evolutionary path. Moreover, given the difficulties in data collection in realities, this study only verifies the developed method in the design, construction, and operation stages of a real building case. Future research can extend the research boundary by including the recycling and reuse phase of a building. Collecting practical data from multiple cases is beneficial for identifying an evolutionary path for promoting the effectiveness of lifecycle BIM implementation under different scenarios.

Supplementary Materials: The following are available online at http://www.mdpi.com/2071-1050/12/23/9988/s1. Supplementary file, Figure S1: Value distribution of the total questionnaire, training set, and testing set, Figure S2: Comparative analysis of different models, Figure S3: The confusion matrix, Table S1: A summary of precision, recall, and F1 score of different values.

Author Contributions: Conceptualization, Q.W. and Z.L.; methodology, Q.W.; software, Y.P.; validation, Z.L.; formal analysis, B.G.; investigation, Y.P.; resources, Q.W.; data curation, B.G.; writing-original draft preparation, Q.W.; writing-review and editing, Q.W. and Z.L. All authors have read and agreed to the published version of the manuscript. 
Funding: This research was funded by the National Key Research and Development Project of the 13th Five-Year plan, grant number 2018YFC0705900 and the Opening Funds of State Key Laboratory of Building Safety and Built Environment and National Engineering Research Center of Building Technology, grant number BSBE2018-08.

Acknowledgments: The authors wish to express their sincere gratitude to the National Key Research and Development Project of the 13th Five-Year plan (2018YFC0705900), and the Opening Funds of State Key Laboratory of Building Safety and Built Environment and National Engineering Research Center of Building Technology (BSBE2018-08) for funding this research project. Appreciation is also due to all members of the research team for their invaluable contributions.

Conflicts of Interest: The authors declare no conflict of interest.

\section{References}

1. Guo, S.; Zheng, S.; Hu, Y.; Hong, J.; Wu, X.; Tang, M. Embodied energy use in the global construction industry. Appl. Energy 2019, 256, 113838. [CrossRef]

2. IAI Alumina Production. Available online: http://www.world-aluminium.org/statistics/alumina-production/ (accessed on 26 August 2020).

3. Hong, J.; Shen, G.Q.; Feng, Y.; Lau, W.S.-T.; Mao, C. Greenhouse gas emissions during the construction phase of a building: A case study in China. J. Clean. Prod. 2015, 103, 249-259. [CrossRef]

4. Hong, J.; Zhang, X.; Shen, G.Q.; Zhang, W.; Feng, Y. A multi-regional based hybrid method for assessing life cycle energy use of buildings: A case study. J. Clean. Prod. 2017, 148, 760-772. [CrossRef]

5. Darko, A.; Chan, A.P.C. Critical analysis of green building research trend in construction journals. Habitat Int. 2016, 57, 53-63. [CrossRef]

6. Ulubeyli, S.; Kazanci, O. Holistic sustainability assessment of green building industry in Turkey. J. Clean. Prod. 2018, 202, 197-212. [CrossRef]

7. Venkataraman, V.; Cheng, J.C.P. Critical Success and Failure Factors for Managing Green Building Projects. J. Arch. Eng. 2018, 24, 04018025. [CrossRef]

8. Ahmad, T.; Thaheem, M.J.; Anwar, A. Developing a green-building design approach by selective use of systems and techniques. Arch. Eng. Des. Manag. 2016, 12, 29-50. [CrossRef]

9. Wu, Z.; Jiang, M.; Cai, Y.; Wang, H.; Li, S. What Hinders the Development of Green Building? An Investigation of China. Int. J. Environ. Res. Public Health 2019, 16, 3140. [CrossRef]

10. An, A.; Powell, C. Health and wellness in commercial buildings: Systematic review of sustainable building rating systems and alignment with contemporary research. Build. Environ. 2020, 171, 106635. [CrossRef]

11. Lu, S.; Wang, Z.; Zhang, T. Quantitative Analysis and Multi-Index Evaluation of the Green Building Envelope Performance in the Cold Area of China. Sustainability 2020, 12, 437. [CrossRef]

12. Hajare, A.; Elwakil, E. Integration of life cycle cost analysis and energy simulation for building energy-efficient strategies assessment. Sustain. Cities Soc. 2020, 61, 102293. [CrossRef]

13. Hwang, B.-G.; Zhao, X.; Tan, L.L.G. Green building projects: Schedule performance, influential factors and solutions. Eng. Constr. Arch. Manag. 2015, 22, 327-346. [CrossRef]

14. Guan, L.; Abbasi, A.; Ryan, M.J. Analyzing green building project risk interdependencies using Interpretive Structural Modeling. J. Clean. Prod. 2020, 256, 120372. [CrossRef]

15. Taurino, R.; Barbieri, L.; Bondioli, F. Surface properties of new green building material after $\mathrm{TiO}_{2}-\mathrm{SiO}_{2}$ coatings deposition. Ceram. Int. 2016, 42, 4866-4874. [CrossRef]

16. Oraee, M.; Hosseini, M.R.; Papadonikolaki, E.; Palliyaguru, R.; Arashpour, M. Collaboration in BIM-based construction networks: A bibliometric-qualitative literature review. Int. J. Proj. Manag. 2017, 35, 1288-1301. [CrossRef]

17. Tang, S.; Shelden, D.R.; Eastman, C.M.; Pishdad-Bozorgi, P.; Gao, X. A review of building information modeling (BIM) and the internet of things (IoT) devices integration: Present status and future trends. Autom. Constr. 2019, 101, 127-139. [CrossRef]

18. Wu, Z.; Chen, C.; Cai, Y.; Lu, C.; Wang, H.; Yu, T. BIM-Based Visualization Research in the Construction Industry: A Network Analysis. Int. J. Environ. Res. Public Health 2019, 16, 3473. [CrossRef] 
19. Volk, R.; Stengel, J.; Schultmann, F. Building Information Modeling (BIM) for existing buildings-Literature review and future needs. Autom. Constr. 2014, 38, 109-127. [CrossRef]

20. Carvalho, J.P.; Bragança, L.; Mateus, R. Optimising building sustainability assessment using BIM. Autom. Constr. 2019, 102, 170-182. [CrossRef]

21. GhaffarianHoseini, A.; Tookey, J.; GhaffarianHoseini, A.; Naismith, N.; Azhar, S.; Efimova, O.; Raahemifar, K. Building Information Modelling (BIM) uptake: Clear benefits, understanding its implementation, risks and challenges. Renew. Sustain. Energy Rev. 2017, 75, 1046-1053. [CrossRef]

22. Jin, R.; Zhong, B.; Ma, L.; Hashemi, A.; Ding, L. Integrating BIM with building performance analysis in project life-cycle. Autom. Constr. 2019, 106, 102861. [CrossRef]

23. Ayman, R.; Alwan, Z.; McIntyre, L. BIM for sustainable project delivery: Review paper and future development areas. Arch. Sci. Rev. 2019, 63, 15-33. [CrossRef]

24. Dutta, S.; Noble, W.; Huang, L.; Zheng, J. Automatic re-planning of lifting paths for robotized tower cranes in dynamic BIM environments. Autom. Constr. 2020, 110, 102998. [CrossRef]

25. Migilinskas, D.; Pavlovskis, M.; Urba, I.; Zigmund, V. Analysis of Problems, Consequences and Solutions for BIM Application in Reconstruction Projects. J. Civ. Eng. Manag. 2017, 23, 1082-1090. [CrossRef]

26. Lee, Y.; Kim, I.; Choi, J. Development of BIM-Based Risk Rating Estimation Automation and a Design-for-Safety Review System. Appl. Sci. 2020, 10, 3902. [CrossRef]

27. Boje, C.; Guerriero, A.; Kubicki, S.; Rezgui, Y. Towards a semantic Construction Digital Twin: Directions for future research. Autom. Constr. 2020, 114, 103179. [CrossRef]

28. Hsu, H.-C.; Chang, S.; Chen, C.-C.; Wu, I.-C. Knowledge-based system for resolving design clashes in building information models. Autom. Constr. 2020, 110, 103001. [CrossRef]

29. Wong, J.K.W.; Zhou, J. Enhancing environmental sustainability over building life cycles through green BIM: A review. Autom. Constr. 2015, 57, 156-165. [CrossRef]

30. Liu, X.; Wang, M.; Fu, H. Visualized analysis of knowledge development in green building based on bibliographic data mining. J. Supercomput. 2018, 76, 3266-3282. [CrossRef]

31. Olawumi, T.O.; Chan, D.W. A scientometric review of global research on sustainability and sustainable development. J. Clean. Prod. 2018, 183, 231-250. [CrossRef]

32. Ansah, M.K.; Chen, X.; Yang, H.; Lu, L.; Lam, P.T. A review and outlook for integrated BIM application in green building assessment. Sustain. Cities Soc. 2019, 48, 101576. [CrossRef]

33. Gao, H.; Koch, C.; Wu, Y. Building information modelling based building energy modelling: A review. Appl. Energy 2019, 238, 320-343. [CrossRef]

34. Pezeshki, Z.; Soleimani, A.; Darabi, A. Application of BEM and using BIM database for BEM: A review. J. Build. Eng. 2019, 23, 1-17. [CrossRef]

35. Jalaei, F.; Jrade, A. Integrating building information modeling (BIM) and LEED system at the conceptual design stage of sustainable buildings. Sustain. Cities Soc. 2015, 18, 95-107. [CrossRef]

36. El-Diraby, T.; Krijnen, T.T.; Papagelis, M. BIM-based collaborative design and socio-technical analytics of green buildings. Autom. Constr. 2017, 82, 59-74. [CrossRef]

37. Chen, J.; Li, Z.; Gong, K. Nondestructive Testing Method Based on Lamb Waves for Localization and Extent of Damage\#. Acta Mech. Solida Sin. 2017, 30, 65-74. [CrossRef]

38. Kittipongvises, S.; Phetrak, A.; Rattanapun, P.; Brundiers, K.; Buizer, J.L.; Melnick, R. AHP-GIS analysis for flood hazard assessment of the communities nearby the world heritage site on Ayutthaya Island, Thailand. Int. J. Disaster Risk Reduct. 2020, 48, 101612. [CrossRef]

39. Liu, Y.; Eckert, C.M.; Earl, C.F. A review of fuzzy AHP methods for decision-making with subjective judgements. Expert Syst. Appl. 2020, 161, 113738. [CrossRef]

40. Wen, Q.; Hong, J.; Liu, G.; Xu, P.; Tang, M.; Li, Z. Regional efficiency disparities in China's construction sector: A combination of multiregional input-output and data envelopment analyses. Appl. Energy 2020, 257, 113964. [CrossRef] 
41. Toledo-Pérez, D.C.; Rodríguez-Reséndiz, J.; Gómez-Loenzo, R.A.; Jáuregui, J.C. Support Vector Machine-Based EMG Signal Classification Techniques: A Review. Appl. Sci. 2019, 9, 4402. [CrossRef]

42. Dreiseitl, S.; Ohno-Machado, L. Logistic regression and artificial neural network classification models: A methodology review. J. Biomed. Inform. 2002, 35, 352-359. [CrossRef]

43. Roman, N.D.; Bre, F.; Fachinotti, V.D.; Lamberts, R. Application and characterization of metamodels based on artificial neural networks for building performance simulation: A systematic review. Energy Build. 2020, 217, 109972. [CrossRef]

44. Feng, J.; Zhang, J.P.; Gao, S.P. Chooseing suitable BIM software for engineering projects based on the fuzzy neural network evaluation model. In Progress in Industrial and Civil Engineering II, Pts 1-4; Yang, W., Liang, J., Eds.; Trans Tech Publications Ltd.: Stafa-Zurich, Switzerland, 2013; Volume 405-408, pp. 3348-3351.

45. Li, Y.-W.; Cao, K. Establishment and application of intelligent city building information model based on BP neural network model. Comput. Commun. 2020, 153, 382-389. [CrossRef]

46. Luo, Z.; Huang, F.; Liu, H. PM2.5 concentration estimation using convolutional neural network and gradient boosting machine. J. Environ. Sci. 2020, 98, 85-93. [CrossRef]

47. Lecun, Y.; Bottou, L.; Bengio, Y.; Haffner, P. Gradient-based learning applied to document recognition. Proc. IEEE 1998, 86, 2278-2324. [CrossRef]

48. Gao, Y.; Gao, L.; Xin-Yu, L.; Yan, X. A semi-supervised convolutional neural network-based method for steel surface defect recognition. Robot. Comput. Manuf. 2020, 61, 101825. [CrossRef]

49. Zhang, W.; Ma, K.; Yan, J.; Deng, D.; Wang, Z. Blind Image Quality Assessment Using a Deep Bilinear Convolutional Neural Network. IEEE Trans. Circuits Syst. Video Technol. 2020, 30, 36-47. [CrossRef]

50. Wu, Z.; Yu, A.T.; Shen, L. Investigating the determinants of contractor's construction and demolition waste management behavior in Mainland China. Waste Manag. 2017, 60, 290-300. [CrossRef]

51. Wu, Z.; Pagell, M. Balancing priorities: Decision-making in sustainable supply chain management. J. Oper. Manag. 2011, 29, 577-590. [CrossRef]

52. Iacovidou, E.; Purnell, P.; Lim, M.K. The use of smart technologies in enabling construction components reuse: A viable method or a problem creating solution? J. Environ. Manag. 2018, 216, 214-223. [CrossRef]

53. Barni, A.; Fontana, A.; Menato, S.; Sorlini, M.; Canetta, L. Exploiting the Digital Twin in the Assessment and Optimization of Sustainability Performances. In Proceedings of the 2018 International Conference on Intelligent Systems (IS), Funchal-Madeira, Portugal, 25-27 September 2018; pp. 706-713.

54. Marefat, A.; Toosi, H.; Hasankhanlo, R.M. A BIM approach for construction safety: Applications, barriers and solutions. Eng. Constr. Arch. Manag. 2019, 26, 1855-1877. [CrossRef]

55. Bosch, A.; Volker, L.; Koutamanis, A. BIM in the operations stage: Bottlenecks and implications for owners. Built Environ. Proj. Asset Manag. 2015, 5, 331-343. [CrossRef]

56. Liu, L.; Ouyang, W.; Wang, X.; Fieguth, P.; Chen, J.; Liu, X.; Pietikäinen, M. Deep Learning for Generic Object Detection: A Survey. Int. J. Comput. Vis. 2020, 128, 261-318. [CrossRef]

57. Park, K.; Kim, D.-H. Accelerating Image Classification using Feature Map Similarity in Convolutional Neural Networks. Appl. Sci. 2018, 9, 108. [CrossRef]

58. He, K.; Zhang, X.; Ren, S.; Sun, J. Deep Residual Learning for Image Recognition. In Proceedings of the 2016 IEEE Conference on Computer Vision and Pattern Recognition (CVPR), Las Vegas, NV, USA, 27-30 June 2016; pp. 770-778.

59. Ji, M.; Liu, L.; Zhang, R.; Buchroithner, M.F. Discrimination of Earthquake-Induced Building Destruction from Space Using a Pretrained CNN Model. Appl. Sci. 2020, 10, 602. [CrossRef]

60. Tanaka, M. Weighted sigmoid gate unit for an activation function of deep neural network. Pattern Recognit. Lett. 2020, 135, 354-359. [CrossRef]

61. Hyvärinen, A.; Köster, U. Complex cell pooling and the statistics of natural images. Netw. Comput. Neural Syst. 2007, 18, 81-100. [CrossRef]

62. Dong, L.; Zhang, H.; Ji, Y.; Ding, Y. Crowd counting by using multi-level density-based spatial information: A Multi-scale CNN framework. Inf. Sci. 2020, 528, 79-91. [CrossRef] 
63. Guo, Z.; Chen, Q.; Wu, G.; Xu, Y.; Shibasaki, R.; Shao, X. Village Building Identification Based on Ensemble Convolutional Neural Networks. Sensors 2017, 17, 2487. [CrossRef]

64. Sun, A.; Lim, E.-P.; Liu, Y. On strategies for imbalanced text classification using SVM: A comparative study. Decis. Support Syst. 2009, 48, 191-201. [CrossRef]

65. Yang, X.; Li, H.; Yu, Y.; Luo, E.; Huang, T.; Yang, X. Automatic Pixel-Level Crack Detection and Measurement Using Fully Convolutional Network. Comput. Civ. Infrastruct. Eng. 2018, 33, 1090-1109. [CrossRef]

Publisher's Note: MDPI stays neutral with regard to jurisdictional claims in published maps and institutional affiliations.

(C) 2020 by the authors. Licensee MDPI, Basel, Switzerland. This article is an open access article distributed under the terms and conditions of the Creative Commons Attribution (CC BY) license (http://creativecommons.org/licenses/by/4.0/). 